\title{
RARE ASSOCIATION OF POSTERIOR EMBRYOTOXON WITH MAXILLARY HYPOPLASIA, VENTRICULAR SEPTAL DEFECT, PULMONARY ATRESIA AND PATENT DUCTUS ARTERIOSUS
}

\author{
M. L. Pandey ${ }^{1}$, Himanshu Goyal2 ${ }^{2}$ Kalpana Sharma ${ }^{3}$, K. P. Chaudhary ${ }^{4}$
}

\section{HOW TO CITE THIS ARTICLE:}

M. L. Pandey, Himanshu Goyal, Kalpana Sharma, K. P. Chaudhary. "Rare Association of Posterior Embryotoxon with Maxillary Hypoplasia, Ventricular Septal Defect, Pulmonary Atresia and Patent Ductus Arteriosus". Journal of Evolution of Medical and Dental Sciences 2014; Vol. 3, Issue 74, December 29; Page: 15621-15624,

DOI: $10.14260 /$ jemds/2014/4110

ABSTRACT: BACKGROUND: Posterior embryotoxon is a congenital anomaly, considered to be a relatively mild disorder and can occur in 15\% of normal eyes. Bilateral posterior embryotoxon associated with maxillary hypoplasia, Ventricular Septal Defect (VSD), Pulmonary Atresia (PA) with Patent Ductus Arteriosus (PDA) is of rare occurrence and hasn't been reported in literature till date. CASE: We report a case of 12 year old female who came to us in eye Out Patient Department for routine eye checkup and on detailed ocular examination we found anteriorly displaced Schwalbe's line. On detailed physical examination and investigations she was found to have pan-systolic murmur and continuous machinery murmur. On Echocardiography, the patient was found to have large perimembranous VSD with PA and PDA. On Oro-dental examination she was found to have maxillary hypoplasia. CONCLUSION: The present case is reported due to the rarity and sporadic character of the condition and its rare association with cardiac defect and maxillary hypoplasia.

KEYWORDS: Posterior Embryotoxon, Ventricular Septal Defect, Maxillary Hypoplasia, Neural Crest Cells.

KEYMESSAGE: Any patient with posterior embryotoxon should be thoroughly examined and investigated to rule out other systemic anomalies associated with this condition.

INTRODUCTION: In 1920, Axenfeld first described a gray-white circular line on the posterior surface of the cornea near the limbus in an otherwise normal person. ${ }^{1}$ He referred to this abnormality as embryotoxon corneae posterius. This gray-white line was later identified histologically as the prominence of Schwalbe's line. ${ }^{2}$

CASE: A 12 year female attended our Eye Out Patient Department for ophthalmic checkup. She was admitted in paediatric ward for dyspnea on exertion and recurrent chest infections. There was no history of any ocular complaints. Family history and birth history were not contributory. Her weight for age and height for age were $17 \mathrm{kgs}$ (Less than $3^{\text {rd }}$ centile) and $123 \mathrm{cms}$ (less than $3^{\text {rd }}$ centile). Her detailed physical examination revealed pan-systolic murmur in left upper para-sternal area associated with thrill and a continuous machinery murmur in pulmonary area in $2^{\text {nd }}$ left intercostal space. Her other systemic examination was normal. On oro-dental examination, she was found to have maxillary hypoplasia (Figure 1). 


\section{CASE REPORT}

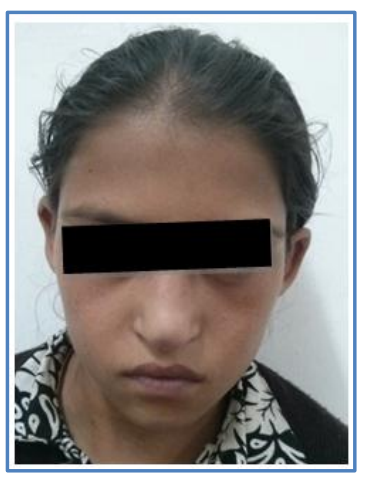

Fig. 1: Maxillary hypoplasia

On ocular examination the unaided visual acuity was $6 / 6$ in both eyes. The cornea showed a glassy white annular membrane $1 \mathrm{~mm}$ all around the cornea in both eyes (Figure 2-4). Slit Lamp examination revealed it to be situated on the posterior surface of the cornea. Gonioscopy revealed the prominence of Schwalbe's ring with insertion of the pectinate strands which were running from the anterior surface of the iris to this ring. Fundus examination did not reveal any abnormality.

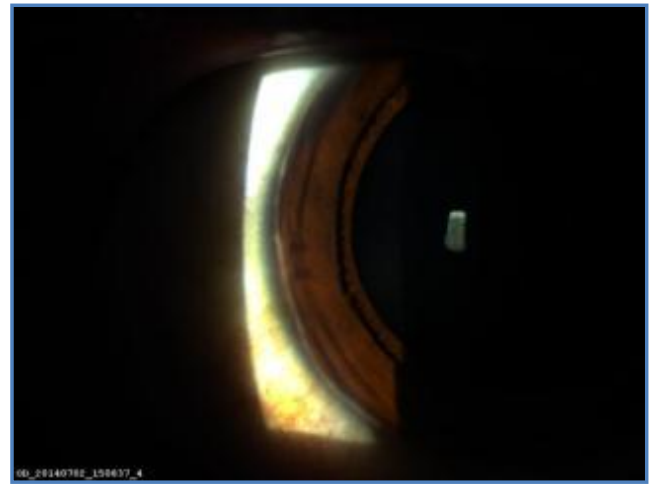

Fig. 2: Right eye showing Posterior Embryotoxon

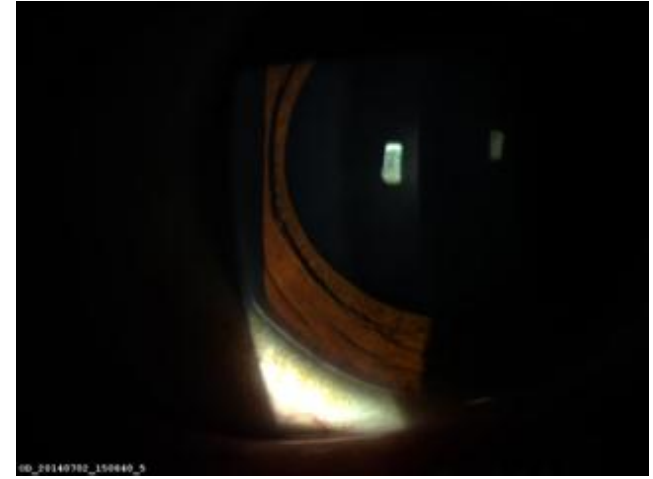

Fig 3: Right eye showing Posterior Embryotoxon

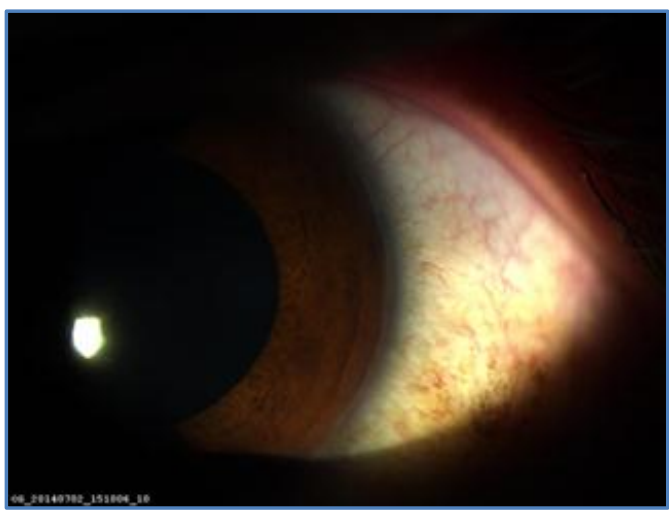

Fig. 4: Left eye showing Posterior Embryotoxon 
Her external ocular examination was normal. She was investigated for glaucoma. Diurnal variation and applanation tonometry did not reveal any change suggestive of the defect.

Her routine laboratory investigations including complete haemogram, liver function tests, renal function tests, lipid profile were all within normal limits. On Echocardiography, the patient was found to have large peri-membranous VSD with PA with PDA. Abdominal ultrasonography, CT scan skull and MRI Spine were normal.

DISCUSSION: Posterior embryotoxon is a congenital anomaly, considered to be a relatively mild disorder and can occur as an isolated defect. However, it can also be detected in association with other ocular and systemic congenital anomalies e.g. Axenfeld-Reiger syndrome, Peters' anomaly, Alagille syndrome and Sclerocornea. Embryologically, posterior embryotoxon is one of the mesenchymal dysgenesis of the anterior ocular segment caused by the abnormal migration of neural crest cells. ${ }^{3,4}$ The cardiac and cranial neural crest derivatives are also responsible for the development of craniofacial mesenchyme including bone, cartilage and connective tissues of the face, and the heart outflow tract including aortic arch/pulmonary artery septum, large arteries wall musculoconnective tissue. ${ }^{5}$

As the trabecular meshwork is also derived from the neural crest, it stands to reason that patients with posterior embryotoxon are predisposed to open-angle glaucoma. ${ }^{6-8}$ Definite cause of the condition is unknown. However, an autosomal hereditary tendency has been noted with familial occurrence in 2 to 3 Generations. ${ }^{9-11}$ The occurrence in this case was sporadic without any other member of the family being affected. It is therefore necessary for the ophthalmologists to do detailed history, examination and necessary investigations to rule out other systemic anomalies associated with posterior embryotoxon.

SUMMARY: This case is unique of its own kind due to rare association of bilateral posterior embryotoxon in the cornea with cardiac anomalies consisting of VSD, PA, PDA and maxillary hypoplasia.

\section{REFERENCES:}

1. Axenfeld T. Embryotoxon corneae posterius. Ber Deutsch Ophthalmol Gesellsch 1920; 42: 301-2.

2. Burian HM, Braley AE, Allen L. External and gonioscopic visibility of the ring of Schwalbe and the trabecular zone. Trans Am Ophthalmol Sot 1954;52:389-428

3. Bahn CF, Falls HF, Varley GA, Meyer RF, Edelhauser HF, Bourne WM. Classification of cornea1 endothelial disorders based on neural crest origin. Ophthalmology 1984; 91: 558 3.

4. Waring GO. Congenital and neonatal cornea1 abnormalities. In: Leibowitz HW, ed. Cornea1 disorders. Clinical diagnosis and management. Philadelphia: WB Saunders, 1984:29-56.

5. Le Lièvre C S, Le Douarin N M. Mesenchymal derivatives of the neural crest: Analysis of chimaeric quail and chick embryos. J. Embryol. Exp. Morphol. 1975; 34: 125-154.

6. Johnston MC, Norden DM. Hazelton RD, Coulombre JL, Coulombre AJ. Origins of avian ocular and periocular tissues. Exp Eye Res 1979; 29: 27-43.

7. Laibson PR, Waring GO. Diseases of the cornea. In: Harley Saunders, 1983:456-514. 


\section{CASE REPORT}

8. Beauchamp GR, Knepper PA. Role of the neural crest in anterior segment development and disease. J Pediatr Ophthalmol Strabismus 1984; 21: 209-14.

9. Waardenberg, P. J. (1932) the human Eye (in German) U. Serne, Erbanlagen Haag.

10. Biozzi, G. \& Lu, gli, L., (1935). Grades Arch. Ophth, 124, 287.

11. Ascher, K, W. (1941) Amer. J. Opth. 24, 615.

\section{AUTHORS:}

1. M. L. Pandey

2. Himanshu Goyal

3. Kalpana Sharma

4. K. P. Chaudhary

\section{PARTICULARS OF CONTRIBUTORS:}

1. Professor, Department of Ophthalmology, Indira Gandhi Medical College, Shimla.

2. Junior Resident, Department of Ophthalmology, Indira Gandhi Medical College, Shimla.

3. Senior Resident, Department of Ophthalmology, Indira Gandhi Medical College, Shimla.
4. Professor and HOD, Department of Ophthalmology, Indira Gandhi Medical College, Shimla.

\section{NAME ADDRESS EMAIL ID OF THE} CORRESPONDING AUTHOR:

Dr. Himanshu Goyal,

\#15, Somson's Colony,

Thandi Sadak,

Malerkotla-148023,

District Sangrur, Punjab.

E-mail: dr.himanshugoyal@yahoo.com

Date of Submission: 11/12/2014.

Date of Peer Review: 12/12/2014.

Date of Acceptance: 18/12/2014.

Date of Publishing: 29/12/2014. 